\title{
Laparoscopic and imaging findings of growing teratoma syndrome
}

\author{
Salih Taşkın, (D) Batuhan Turgay, (D) Yavuz Emre Şükür, (D) Fırat Ortaç \\ Department of Obstetrics and Gynecology, Ankara University Faculty of Medicine, Ankara, Turkey
}

\section{Abstract}

Growing teratoma syndrome (GTS) occurs during post-treatment observation of ovarian malignant germ cell tumors. The characteristic features of this syndrome are normal tumor marker levels and evident tumoral mass or implants on imaging studies. We report a case of GTS in a 22-yearold woman with a malignant germ cell tumor. After staging surgery and chemotherapy, computed tomography showed peritoneal implants. Laparoscopy was planned to exclude malignant recurrence. During laparoscopy, smooth and pink-colored lesions were seen at the lateral pelvic wall. Histopathologic evaluation reported mature teratoma tissue with extensive mature glial components. GTS is not a malignant condition and the benefit of radical surgical intervention in cases without mass-related complication is not proven. GTS should be kept in mind after primary treatment of ovarian immature teratoma.

Keywords: Growing teratoma syndrome, laparoscopy, management

Received: 21 February, 2019 Accepted: 27 April, 2020

\section{Introduction}

A 19 year-old nulli-gravid woman with massive ascites and abdominal mass was referred to our clinic. Laboratory examination revealed elevated tumor markers (AFP: 922.4 ng/mL, CA 125=331 U/mL, CA 19-9=418.1 U/mL). Computed tomography $(\mathrm{CT})$ revealed a huge mass filling the abdomen and a large volume of ascites (Figure 1). Midline laparotomy was performed due to the pre-diagnosis of ovarian malignant germ cell tumor. During the intraoperative observation, a huge leftside ovarian mass and massive peritoneal-omental implants were detected. Subsequently, left salphingo-oophorectomy, total omentectomy, peritonectomy, and bilateral pelvic and para-aortic lymph node dissection were performed. There was no residual tumor at the end of the surgery. Final pathology was stage IIIC immature teratoma with retroperitoneal lymph node involvement. Four cycles of bleomycine-etoposide-paclitaxel chemotherapy was administered. At the end of the treatment tumor markers were within normal range.

Two months after chemotherapy and six months after the operation, during a routine follow-up visit, CT examination revealed peritoneal implants. Tumor markers remained within normal ranges and the patient was asymptomatic. Recurrence of malignant germ cell tumor was not expected and so

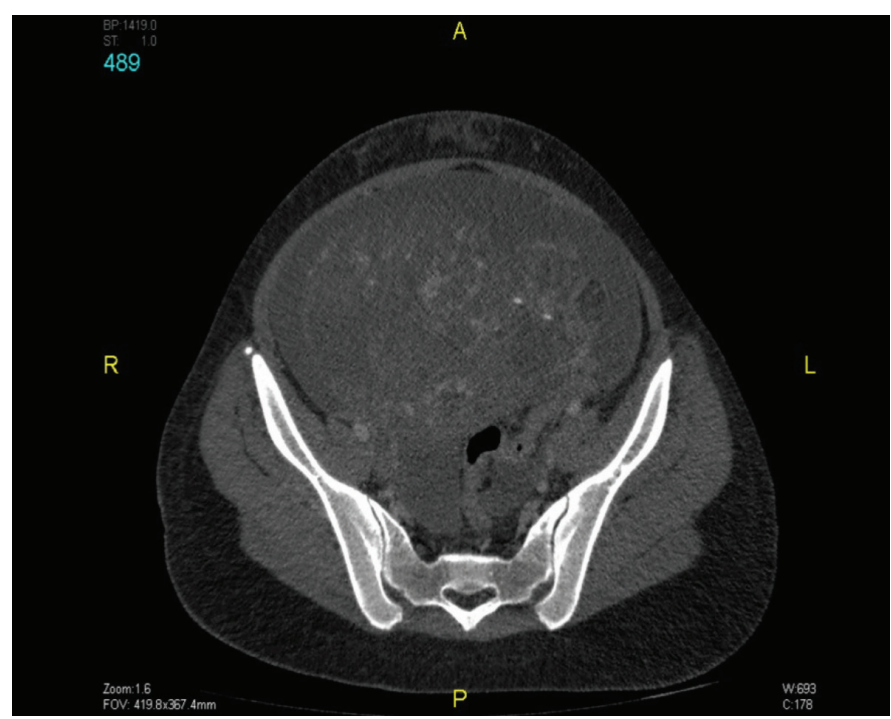

Figure 1. Preoperative computerized tomography image of the abdominal mass 
laparoscopy for further differential diagnosis was scheduled.

During laparoscopy, smooth and pink-colored lesions were detected at the lateral pelvic wall (Video 1). These lesions were superficial and easily removable (Figure 2). There was no invasion into the sub-tissue. The operation was completed after taking multiple biopsies from the lesions detected.

There were no postoperative complications. Histopathological evaluation revealed mature teratoma tissue with extensive mature glial components. The diagnosis was growing teratoma syndrome (GTS) and adjuvant therapy was considered unnecessary. The patient is alive without recurrence since the initial diagnosis of germ cell tumor 15 months earlier and is followed up every three months. Information consent was given by the patient for this report.

\section{Discussion}

GTS is characterized by the presence of tumoral lesions, growing during or after chemotherapy being given for malignant germ cell tumors, and when tumor markers are within normal range. It is a rare condition and is more common in men with testicular germ cell tumors than in women with ovarian germ cell tumors (1). The incidence of GTS is unknown. The median (range) interval between the diagnosis of ovarian immature teratoma and GTS has been reported to be nine (4-55) months (2). Although approximately 100 cases have been reported in the English literature, a recent article found that GTS is more common than previously reported, with an incidence of $40 \%$ in patients who had already undergone surgery $(3,4)$. Mostly, it occurs in the pelvic region but there are also some patients with extrapelvic disease, such as lung, mediastinum, central nervous system, spleen and diaphragm (5-7).

The benefit of radical surgical intervention in cases without mass-related complication has not been proven. Disease can be asymptomatic and totally stable over a long period, which raises the question of a more conservative surgical approach in patients with massive peritoneal spread (8). Radical surgeries,

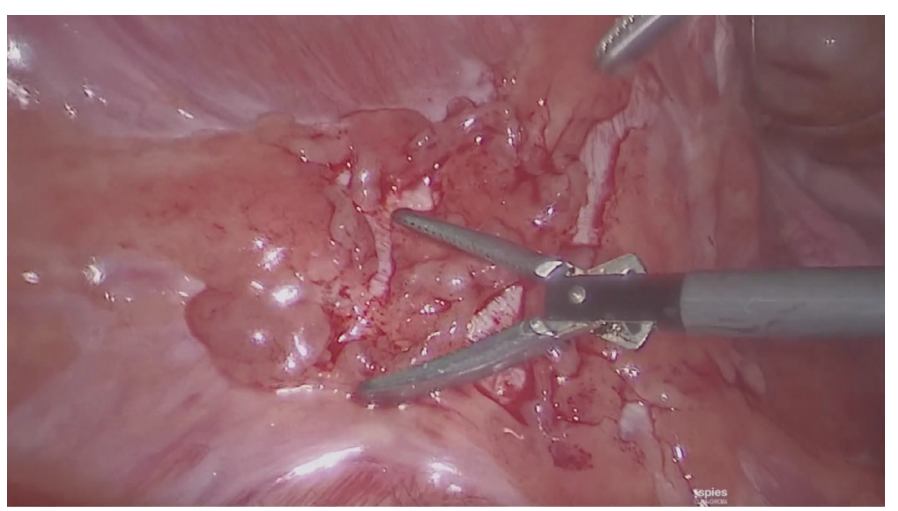

Figure 2. Laparoscopic image of the peritoneal implants such as peritonectomy, splenectomy or bowel resection may be needed to achieve complete debulking (9). However, these radical interventions are not standard in asymptomatic GTS (3). Radical surgery should be performed in symptomatic patients as a final resort.

As has been noted, this condition can be managed by observation without any therapeutic intervention. However, GTS should be definitively diagnosed and malignant germ cell tumor recurrence should be excluded prior to a final management decision. Imaging studies may not be sufficient to make the differential diagnosis between malignant recurrence and GTS. Laparoscopy is thus helpful to distinguish GTS from malignant recurrence and to preclude unnecessary chemotherapy. In addition, laparoscopy can be helpful to observe the abdomen directly and to obtain tissue for a definitive diagnosis.

\section{Video 1. Laparoscopic findings of peritoneal implants

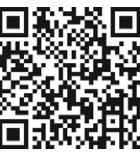

https://www.doi.org/10.4274/jtgga.galenos.2020.2019.0034.video1

Informed Consent: Information consent was given by the patient for this report.

Conflict of Interest: No conflict of interest was declared by the authors.

Financial Disclosure: The authors declared that this study received no financial support.

\section{References}

1. Logothetis CJ, Samuels ML, Trindade A, Johnson DE. The growing teratoma syndrome. Cancer 1982; 50: 1629-35.

2. Zagamé L, Pautier P, Duvillard P, Castaigne D, Patte C, Lhommé C. Growing teratoma syndrome after ovarian germ cell tumors. Obstet Gynecol 2006; 108: 509-14.

3. Van Nguyen JM, Bouchard-Fortier G, Ferguson SE, Covens A. How common is the growing teratoma syndrome in patients with ovarian immature teratoma? Int J Gynecol Cancer 2016; 26: 1201-6.

4. Wang D, Zhu S, Jia C, Cao D, Wu M, Shen K, et al. Diagnosis and management of growing teratoma syndrome after ovarian immature teratoma: A single center experience. Gynecol Oncol 2020; 157: 94-100.

5. Saso S, Galazis N, Iacovou C, Kappatou K, Tzafetas M, Jones B, et al. Managing growing teratoma syndrome: new insights and clinical applications. Future Sci OA. 2019; 5: FSO419.

6. Zheng R, Devin CL, O'Malley T, Palazzo F, Evans NR 3rd. Surgical management of growing teratoma syndrome: robotic-assisted thoracoscopic resection of mediastinal teratoma. Surg Endosc. 2020; 34: 1019-23.

7. Tsuyuguchi S, Sugiyama K, Kinoshita Y, Kolakshyapati M, Takayasu T, Usui S, et al. Primary and Recurrent Growing Teratoma Syndrome 
in Central Nervous System Nongerminomatous Germ Cell Tumors: Case Series and Review of the Literature. World Neurosurg 2020; 134: e360-71.

8. Bentivegna E, Gonthier C, Uzan C, Genestie C, Duvillard P, Morice P, et al. Gliomatosis peritonei: a particular entity with specific outcomes within the growing teratoma syndrome. Int $\mathrm{J}$ Gynecol Cancer 2015; 25: 244-9.
9. Bentivegna E, Azaïs H, Uzan C, Leary A, Pautier P, Gonthier C, et al. Surgical Outcomes After Debulking Surgery for Intraabdominal Ovarian Growing Teratoma Syndrome: Analysis of 38 Cases. Ann Surg Oncol 2015;22 (Suppl 3): 964-70. 